\title{
BMJ Open Awareness and attitudes of the Lebanese population with regard to physician-pharmaceutical company interaction: a survey study
}

\author{
Ahmad Ammous, ${ }^{1}$ Savo Bou Zein Eddine, ${ }^{1}$ Alia Dani, ${ }^{1}$ Jana Dbaibou, ${ }^{1}$ \\ Jose M El-Asmar, ${ }^{1}$ Liane Sadder, ${ }^{1}$ Elie A Akl ${ }^{2,3}$
}

To cite: Ammous A, Bou Zein Eddine S, Dani A, et al. Awareness and attitudes of the Lebanese population with regard to physicianpharmaceutical company interaction: a survey study. BMJ Open 2017;7:e013041. doi:10.1136/bmjopen-2016013041

- Prepublication history and additional material is available. To view please visit the journal (http://dx.doi.org/ 10.1136/bmjopen-2016013041).

AM, SBZE, AD, JD, JME-A and LS contributed equally to the work and qualify as first authors.

Received 24 June 2016 Revised 10 February 2017 Accepted 13 February 2017

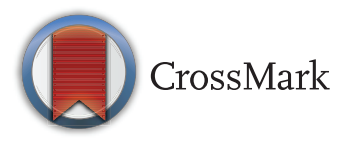

${ }^{1}$ Faculty of Medicine, American University of Beirut, Lebanon

${ }^{2}$ Department of Internal Medicine, American University of Beirut, Lebanon ${ }^{3}$ Department of Clinical Epidemiology and Biostatistics, McMaster University, Hamilton, Ontario, Canada

Correspondence to Dr Elie Akl; ea32@aub.edu.lb

\section{ABSTRACT}

Objective: To assess the awareness and attitudes of the general public in Lebanon regarding the interactions between physicians and pharmaceutical companies.

Setting: Primary healthcare clinics and shopping malls in the Greater Beirut Area.

Participants: 263 participants completed the questionnaire, of whom $62 \%$ were female and $38 \%$ were male. Eligible participants were Arabic-speaking or English-speaking adults (age $\geq 18$ years) residing in Lebanon for at least 5 years.

\section{Primary and secondary outcome measures:}

Awareness, attitudes and beliefs of the general public.

Results: 263 out of 295 invited individuals (89\% completion rate) completed the questionnaire. While the majority of participants were aware of pharmaceutical company presence (or absence) in physicians' offices (range of $71-76 \%$ across questions), smaller percentages were aware of giftrelated practices of physicians (range of 26-69\% across questions). $40 \%$ thought that the acceptance of small gifts or meals by physicians is wrong/unethical. The percentage of participants reporting lower trust in physicians due to their participation in various pharmaceutical company-related activities ranged from $12 \%$ to $45 \%$ (the highest percentage being for large gifts). Participants who reported receiving free medication samples were significantly more likely to consider physicians' acceptance of small gifts as 'not a problem' than 'unethical' $(\mathrm{OR}=1.53 ; \mathrm{p}=0.044)$.

Conclusions: Participants in our survey were generally more aware of pharmaceutical company presence (or absence) in physicians' offices than of gift-related practices of physicians. While the level of trust was not affected for the majority of participants for various types of interactions, it was affected the most for accepting large gifts.

\section{INTRODUCTION}

The interaction between pharmaceutical companies and physicians is a common

\section{Strengths and limitations of this study}

- To the best of our knowledge, this is the first survey on this topic to be conducted in the Middle East region.

- One of the strengths of our study is the inclusion of patients (from primary healthcare clinics) and non-patients (from malls). This increases the external validity of our findings.

- We conducted a pilot test in order to ensure a thorough understanding of the questions among participants and used a validated questionnaire.

- One of the limitations is that the translated Arabic version was not formally validated.

- Another limitation is that our sample is recruited from the Greater Beirut Area, exclusive of other Lebanese areas.

practice in health. ${ }^{1}$ These interactions include offering gifts, financial support and other beneficial favours to physicians. ${ }^{1}$ Pharmaceutical companies claim that these interactions serve to educate and inform physicians of their products. ${ }^{2}$ However, a systematic review of the literature suggested that such interactions are associated with higher prescribing frequency, higher prices and lower quality of drugs prescribed. ${ }^{3}$

These interactions create a conflict of interest for physicians between the perceived obligations towards a pharmaceutical company and the best interests of their patients. ${ }^{4}$ Additionally, physician-pharmaceutical company interactions may affect the general public's trust in their physicians. Lack of trust in the healthcare system has been shown to be associated with decreased patient satisfaction and lower adherence to treatment and screening recommendations. ${ }^{5-7}$

We have not identified any published data about the extent and nature of interaction between physicians and pharmaceutical companies in Lebanon. However, we have 
recently collected data (unpublished) showing that these interactions are common and involve a variety of incentives including stationary equipment, furniture and travel support. In response to concerns about these interactions, the Lebanese Ministry of Public Health published a code of ethics for medicinal products promotion on 31 May $2016 .{ }^{8}$

Owing to its potential effect on patient care, a number of studies have tried to assess the knowledge, beliefs and attitudes of patients towards this relationship. ${ }^{9-11}$ A recently published systematic review found a lower awareness among patients of physicians' receipt of personal gifts relative to office-use gifts (eg, stationery). ${ }^{12}$ Also, there is greater acceptability of the office-use gifts over personal gifts. ${ }^{12}$ The systematic review analysed data from 20 studies, none of which were conducted in Lebanon, indicating a knowledge gap about the patients' perspectives in Lebanon.

The objective of this study was to investigate the awareness and attitudes of the Lebanese general population concerning physician-pharmaceutical company interactions.

\section{METHODS}

\section{Study population}

Eligible participants included Arabic-speaking and English-speaking adults (age $\geq 18$ years) residing in Lebanon for at least 5 years. We recruited two types of participants:

- Individuals in the waiting rooms of primary healthcare clinics. Our sampling frame consisted of the list of primary healthcare clinics in the Greater Beirut Area provided by the ministry of public health.

- Individuals in shopping malls. Our sampling frame consisted of the list of malls in the Greater Beirut Area provided by the Directory of Exports and Industrial Firm in Lebanon.

We excluded individuals working as staff in recruitment sites. The principal investigator contacted the eligible primary healthcare clinics and shopping mall directors asking for permission to distribute the surveys in their premises.

\section{Participant recruitment}

First, we phoned the directors of primary healthcare clinics and shopping malls to obtain approval for conducting our study on their premises.

Then, over several days, members of the team presented to the clinics where they approached potential participants and recruited them in a sequential manner. Similarly, members of the team visited malls where they randomly approached individuals and invited them to participate.

\section{Survey tool}

We adopted our survey tool from a validated, selfadministered questionnaire designed by Green et a ${ }^{\ominus}$ (refer to online supplementary appendix A). We translated the questionnaire from English to Arabic and then back translated it to English (Arabic version available on demand). The survey included 40 questions addressing the following:

- Demographic characteristics $(\mathrm{n}=8)$;

- Awareness $(\mathrm{n}=13)$;

- Attitudes $(\mathrm{n}=11)$

- Beliefs $(\mathrm{n}=8)$.

\section{Data collection}

We collected data between January and March of 2015. Members of the research team were present in the waiting areas and shopping malls and handed the survey to eligible individuals who consented to participate. The Institutional Review Board (IRB) at the American University of Beirut approved this consent procedure.

The team members gave the participants the needed time and privacy to complete the survey. They distributed the surveys according to the participants' language preference and were available to answer any questions.

\section{Data analysis}

One team member entered data into SPSS statistical software and a second one verified them. We conducted a descriptive analysis of all variables. After assessing the distribution of answers, and similar to the approach by Green $e t a l,{ }^{9}$ we collapsed some of the answer options (see online supplementary appendix A). We calculated percentages for the categorical variables and then presented the data in a table format for the demographics section and in graphs for each of three categories (awareness, attitudes and beliefs). Also, we conducted a stratified analysis by type of participant. Since we found significant differences for only 2 out of 32 variables (excluding demographic questions), we report here overall results for all participants.

In addition, we conducted a regression analysis to assess the association between the attitudes regarding the appropriateness of physicians accepting small gifts and the following demographic characteristics: age, sex, education, receiving free medical samples and use of prescribed medication.

\section{Sample size calculation}

We calculated the sample size according to the following formula: $\mathrm{N}=(\mathrm{z}) 2(\mathrm{p})(\mathrm{q}) /(0.05) 2$. We identified no studies on this topic conducted in Lebanon, so we estimated the level of awareness to be close to that in Turkey $(80 \% ; \mathrm{p}=0.8) .{ }^{11}$ This yielded a sample size of $\mathrm{N}=246$. Finally, the target recruitment size was equal between the two groups of participants (individuals at primary healthcare clinics and mall attendees).

\section{RESULTS}

We invited individuals in the waiting rooms of five primary healthcare clinics and in the food courts of four 
shopping malls in Greater Beirut. Out of 295 individuals who agreed to participate, 263 fully completed the questionnaire (89\% completion rate). Individuals declined to participate either for getting called by the physician in the primary care clinic setting, or for being short of time in the mall setting.

\section{Participants' characteristics}

Table 1 shows the demographic characteristics of participants. The age range for the majority of respondents was $18-49$ years $(79 \%)$. They were predominantly female $(62 \%)$, and $48 \%$ had an educational level less than high school. The majority had a low annual household income $(<\mathrm{US} \$ 10000 ; 71 \%)$, and reported currently using prescription medications $(77 \%)$.

\begin{tabular}{lc} 
Table 1 Demographics & \\
\hline & $\begin{array}{c}\text { Frequency } \\
\text { (percentage) }\end{array}$ \\
Characteristics (N) & \\
\hline Age (263) & $206(79)$ \\
$18-49$ years & $41(15)$ \\
$50-64$ years & $16(6)$ \\
$65-80$ years & \\
Sex (258) & $163(63)$ \\
Female & $124(48)$ \\
Education (258) & $70(27)$ \\
Less than high school graduate & $64(25)$ \\
High school graduate or some college & \\
College graduate or more & $167(71)$ \\
Annual household income (235) & $58(25)$ \\
$\quad<U S \$ 10000$ & $10(4)$ \\
US\$10 000-US\$30 000 & $193(74)$ \\
>US $\$ 30$ 000 & $173(71)$ \\
Have a personal healthcare provider (261) & $96(37)$ \\
Satisfied with the healthcare provider $(242)$ & \\
Received free medication samples in & \\
past year (259) & \\
Currently use prescription & \\
medications (262) & \\
\hline
\end{tabular}

\section{Awareness of gifts}

Figure 1 reports the participants' awareness of pharmaceutical company presence in physicians' offices. A majority of participants were aware of whether or not (answered 'yes' or 'no' as opposed to 'I don't know') the following were present in the physicians' waiting room: drug company advertisements $(76 \%)$, items with logos on them $(74 \%)$ and patient education materials $(75 \%)$. Seventy-four per cent were aware that drug representatives visit the clinic. However, only 35\% indicated that they knew whether or not office staff ate lunches paid for by the drug companies.

Figure 2 shows the respondents' level of awareness of a number of gift-related practices of physicians. A minority of participants knew whether or not their physician accepted large gifts $>$ US $\$ 100(29 \%)$, went on trips paid for by the drug companies $(30 \%)$, accepted small gifts $<$ US $\$ 100(31 \%)$, conducted research for drug companies $(32 \%)$ or accepted drug company meals (26\%). However, more participants were aware of whether or not physicians attended drug companies' social activities (41\%), gave lectures for the drug companies $(46 \%)$ and used drug company pens or notepads $(69 \%)$. These figures exclude the number of participants who responded with either 'don't know' or 'don't care'.

\section{Attitudes about gifts}

Figure 3 shows the percentage of participants who agreed with a series of statements about physicians' acceptance of small gifts or meals and those who disagreed: accepting small gifts or meals influences physicians' prescribing behaviours $(44 \%$ agreed, $22 \%$ disagreed); the practice is wrong/unethical $(40 \%$ agreed, $34 \%$ disagreed); accepting meals makes patients wait too long ( $34 \%$ agreed, $35 \%$ disagreed); it is acceptable as long as gifts are of little monetary value (39\% agreed, $30 \%$ disagreed) and it is not problematic (46\% agreed, $30 \%$ disagreed).

We used a multinomial logistic regression analysis to explore what factors are associated with the perceptions

Figure 1 Awareness of pharmaceutical company presence in physicians' offices.

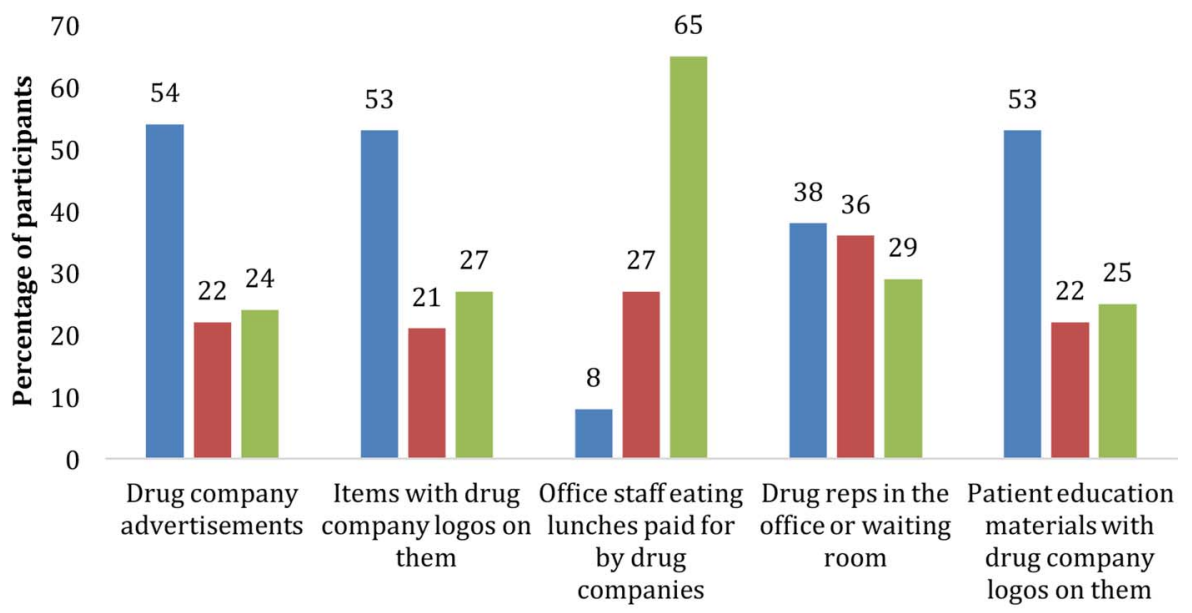

Yes No Don't know 


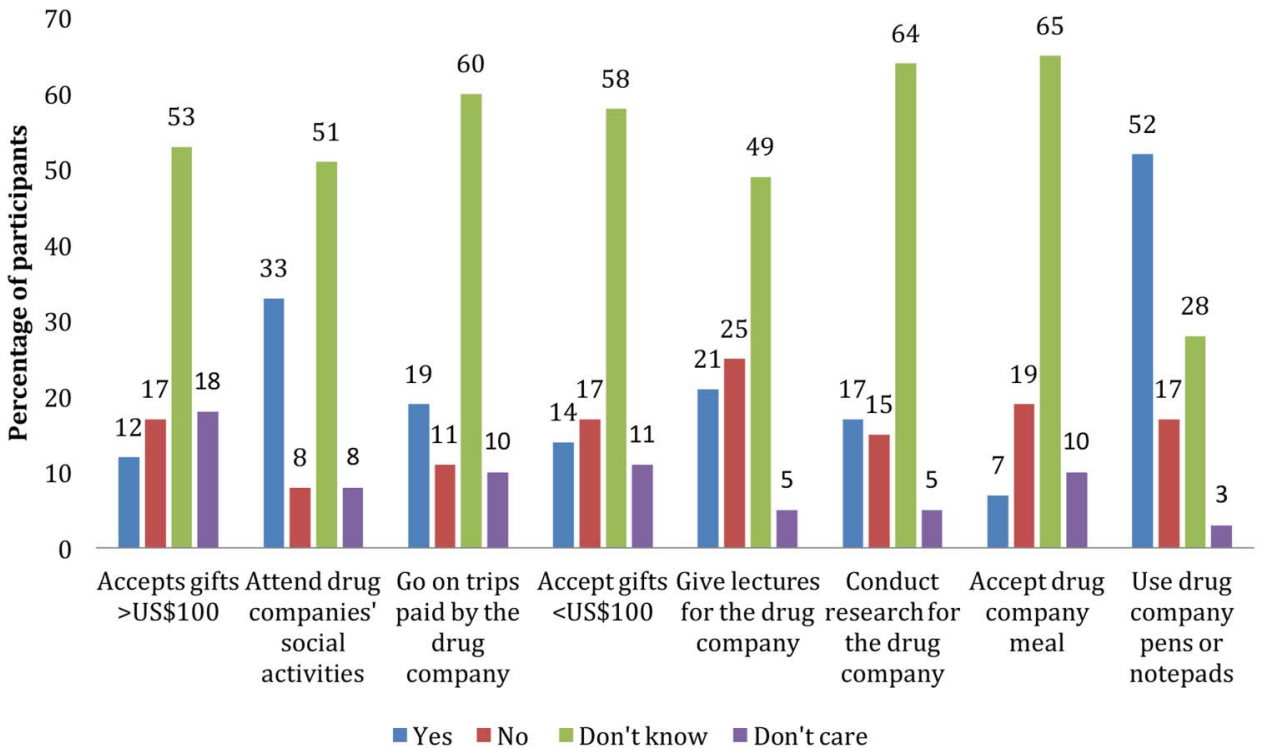

Figure 2 Knowledge of physician engagement in a variety of activities with pharmaceutical companies.

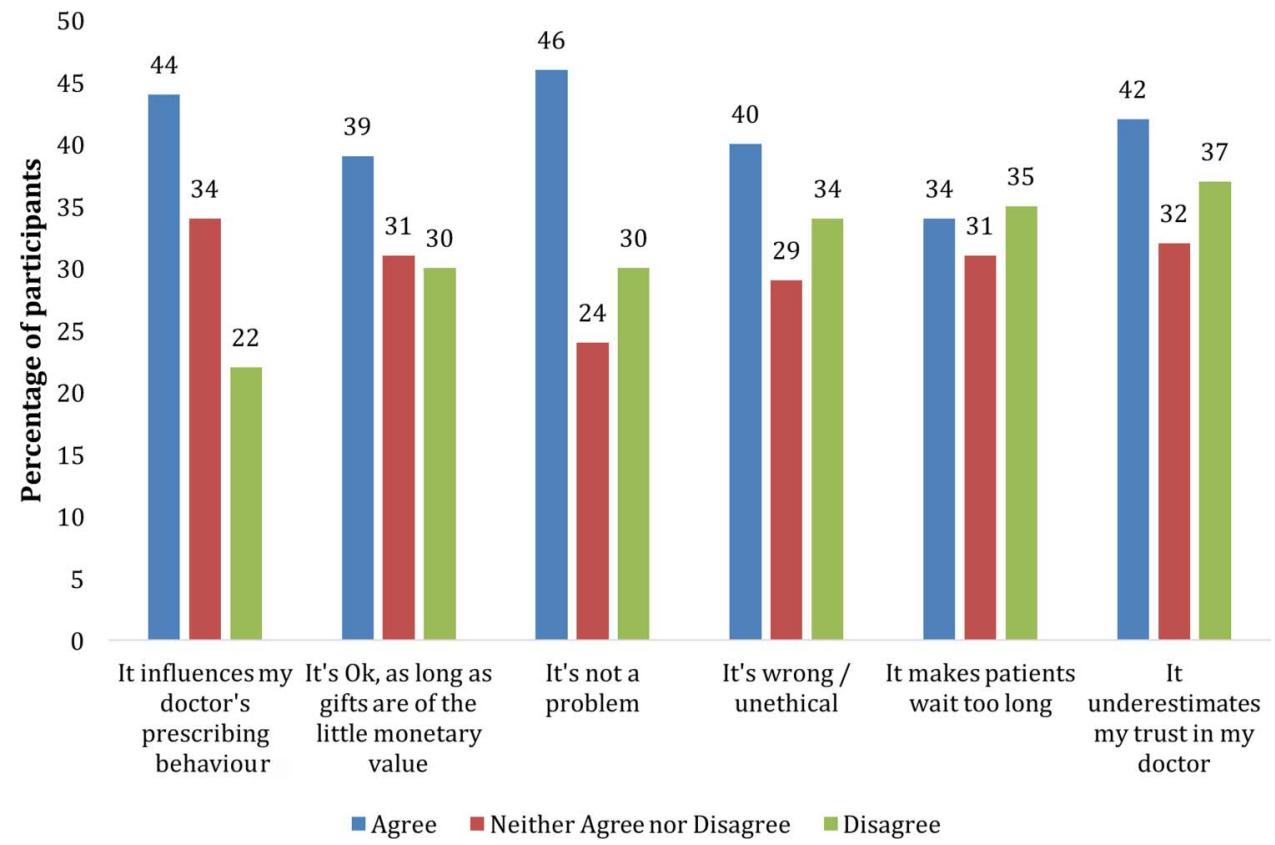

Figure 3 Attitude towards physicians accepting small gifts or meals.

of the appropriateness of physicians accepting small gifts. We found that participants who reported receiving free medication samples were significantly more likely to consider it 'not a problem' $(\mathrm{OR}=1.53$; $\mathrm{p}=0.044$; reference category: considering it 'wrong/ unethical').

Figure 4 shows the participants' attitudes about various professionals, including doctors, accepting these small gifts or meals. The percentage of respondents reporting that it was 'wrong/unethical' for doctors to accept gifts from drug company representatives (45\%) was lower than that for judges to accept gifts from lawyers $(66 \%)$, sports referees to accept gifts from players whose games they officiate $(59 \%)$ and politicians to accept gifts from lobbyists (69\%).

\section{Impact on trust in physicians}

Figure 5 reports the percentage of participants reporting lower trust in physicians related to their participation in various activities: using drug company pens or notepads (12\%), accepting gifts $>$ US $\$ 100(45 \%)$, going on trips paid for by the drug company $(30 \%)$ and accepting gifts $<\mathrm{US} \$ 100(38 \%)$. It is worth noting that there is a substantial percentage of participants who reported that they had more trust in their physician if he/she had a relationship with pharmaceutical companies. This was 


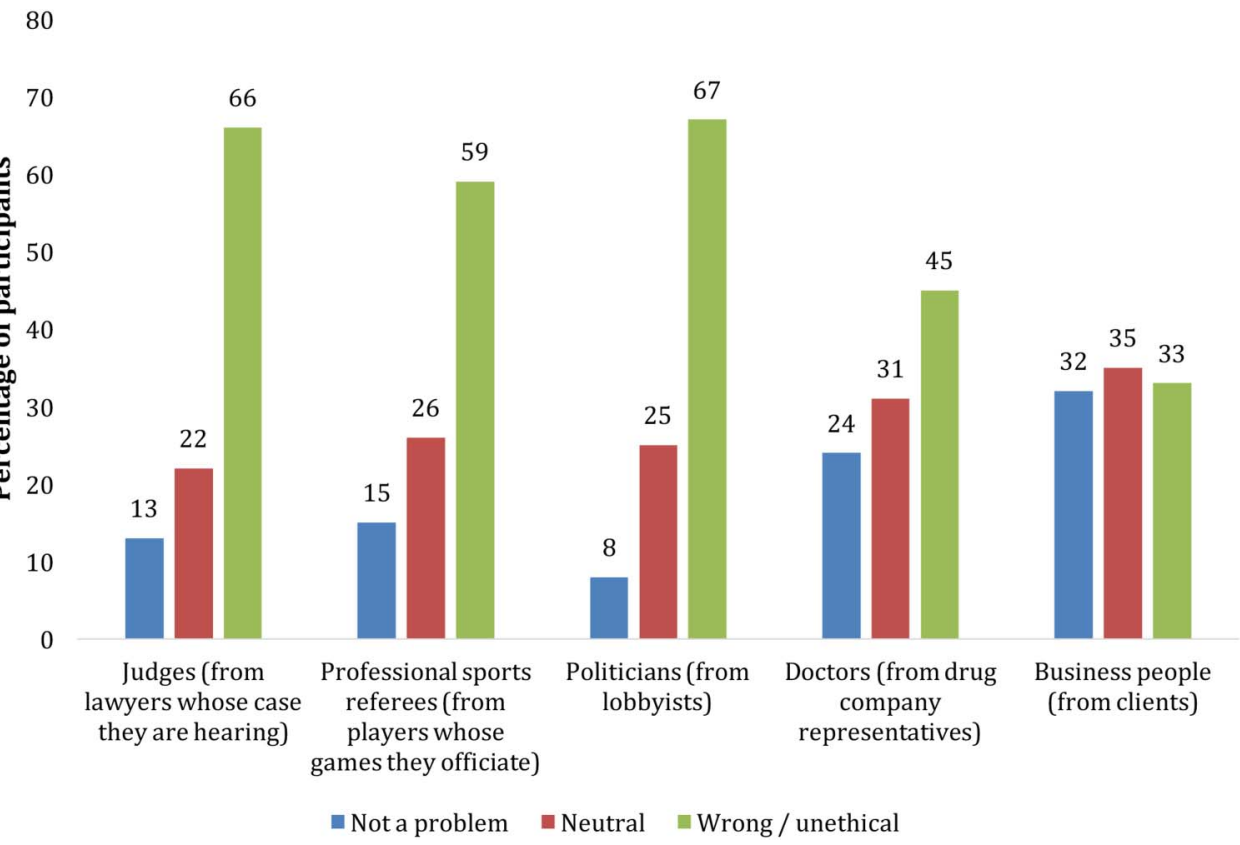

Figure 4 Attitudes about various professionals accepting gifts or meals.

Figure 5 Effect of physician participation in various activities on patient trust.

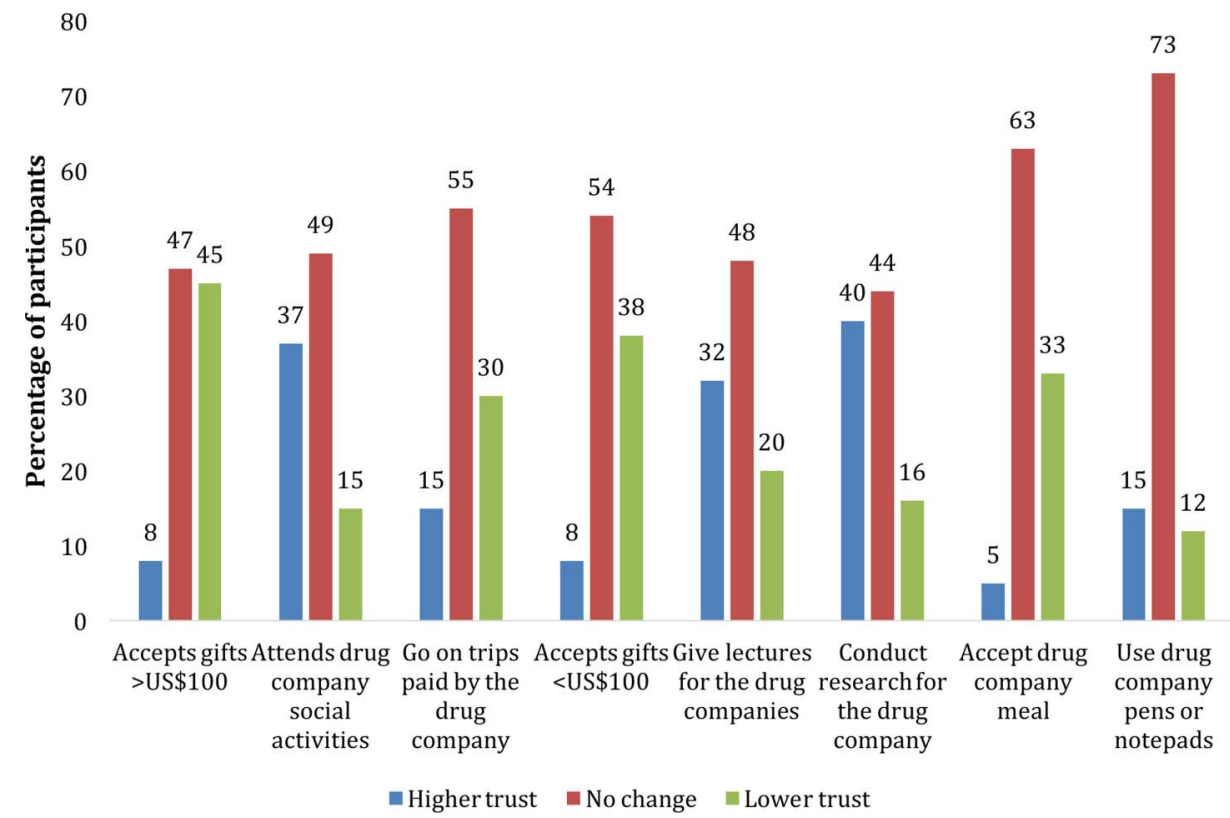

mainly clear with regard to physicians conducting research for the pharmaceutical company ( $40 \%$ had an increased trust).

\section{DISCUSSION}

We aimed to investigate the awareness and attitudes of the Lebanese general population concerning physicianpharmaceutical company interactions. While the majority of participants were aware of pharmaceutical company presence (or absence) in physicians' offices, smaller percentages were aware of gift-related practices of physicians. A minority thought that accepting small gifts or meals by physicians is wrong/unethical and reported lower trust in physicians due to their participation in various pharmaceutical company-related activities. Receiving free medication samples was associated with considering physicians' acceptance of small gifts as 'not a problem'.

An interesting finding is the higher level of awareness in relation to pharmaceutical company presence (or absence) in physicians' offices compared with that of gift-related practices of physicians. One likely explanation is that the company presence in the clinic is typically noticeable (eg, drug company advertisements, items and education material with drug company logos on 
them). On the other hand, most of the interactions of physicians with drug companies are not (eg, conduct research for the drug company, personal gifts, going on trips). This highlights the need for transparency and disclosure by physicians.

We are aware of other studies that have assessed similar outcomes in other countries. A 2008 study conducted in the USA found that $82 \%$ of the participants were aware of the presence of pens or notepads in physicians' offices, as compared with $69 \%$ in our study. ${ }^{9}$ The percentages of participants who were aware of physicians accepting gifts $>$ US $\$ 100$, gifts $<$ US $\$ 100$ and trip invitations were, respectively $12 \%, 16 \%$ and $34 \%$ in the USA, and $29 \%, 31 \%$ and $30 \%$ in Lebanon.

The fact that a minority of respondents thought that accepting small gifts or meals by physicians is wrong suggests that the public either does not consider this issue from an ethical perspective or does not consider it ethically wrong.

While we cannot state whether or not a majority of the participants believe the nature of this interaction is unethical, it is evident that some individuals (40\%) would be opposed to this practice and believe it affects their physician's prescribing behaviour (44\%). Interestingly, the question addressing the ethicality of similar practices (accepting meals and small gifts) with other professions indicated that the respondents might have different standards or expectations across professions. Fewer participants thought that physicians' acceptance of meals or small gifts from pharmaceutical companies was wrong compared with equivalent situations with judges, referees and politicians.

The percentage of participants who believed gifts and interactions between physicians and pharmaceutical companies affect physicians' prescribing behaviour was $41 \%$ in the USA in 2009, which is comparable to the $44 \%$ in our study. ${ }^{10}$ In Turkey, $71 \%$ of patients admitted to primary healthcare centres in 2004 agreed that accepting gifts from the drug companies is not ethical. ${ }^{11}$ In Pakistan, only $9 \%$ of patients attending outpatient clinics in 2000 agreed that it is inappropriate for doctors to accept gifts from pharmaceutical companies. ${ }^{13}$

The fact that a minority of participants reported lower trust in response to the participation of physicians in various activities suggests that relatively few of them made a connection between physicians' practices and their behaviours. As other studies have indicated, ${ }^{10}$ patients' mistrust is related to the possibility that physicians select drugs that are more expensive, less efficacious and cause higher side effects. Notably, there is a substantial percentage of participants who reported that they had more trust in their physician if he/she had a relationship with pharmaceutical companies. We hypothesise that this is due to the belief that close interaction between the two leads to enhanced physician's awareness of the newest pharmaceutical innovations.

In contrast to our study, participants in a study conducted in the USA indicated a greater decrease in their level of trust on knowing that their physician was accepting monetary gifts as well as going on trips paid for by drug companies. As an illustration, on investigating the change in the level of trust when pharmaceutical companies offer paid trips to physicians, $55 \%$ of the Lebanese population showed no change in the level of trust, while $30 \%$ reported lower trust. Conversely, the study conducted on the American sample showed that $58 \%$ reported a decrease in the level of trust in physicians accepting paid trips by pharmaceutical companies, while $38 \%$ had no change in their level of trust. ${ }^{9}$ These findings might suggest that the Lebanese population may be less aware of the potential harm of these interactions than the American population.

As a comparison, the percentages of participants reporting lower trust in physicians related to their acceptance of gifts $>$ US $\$ 100$ and to trips paid for by the drug company were respectively ' $<50 \%$ ' and $58 \%$ (2008) in the US survey, as compared with $45 \%$ and $30 \%$ in our survey. ${ }^{9}$

We have used a convenient sampling approach by restricting our eligibility to residents of the Greater Beirut Area. The resulting high proportion of female and young (18-49) individuals among participants may have introduced sampling bias. Still, our sample is fairly representative of the general Lebanese population. Indeed, on the basis of data reported in the World Factbook, ${ }^{14}$ about $44 \%$ of the Lebanese population reside in the Greater Beirut Area. Moreover, representativeness is improved by the inclusion of patients (from primary healthcare clinics) and the general public (from malls).

In terms of policy implications, there is a definite need to raise awareness among the Lebanese population about the potentially negative impacts of physician-industry interactions on the quality and cost of their healthcare. On a broader level, there is a need for system-level interventions to regulate physician-industry interactions. ${ }^{15}$ These may include self-regulation (eg, voluntary codes of practice) and governmental regulations. The ultimate aim would be to minimise any negative effects of the physician-pharmaceutical company interactions and ultimately improve patient outcomes. Future research should assess the actual extent of the interaction in Lebanon, as well as the effect of raising awareness among the general population on their attitudes towards this interaction.

\section{CONCLUSION}

While the majority of participants were aware of pharmaceutical company presence in physicians' offices, smaller percentages were aware of gift-related practices of physicians. A minority thought that accepting small gifts or meals by physicians is wrong/unethical and reported lower trust in physicians due to their participation in various pharmaceutical company-related activities.

Contributors EA, AA, SBZE, AD, JD, JME-A and LS contributed to the conception and design of the search strategy and to the data abstraction, data 
synthesis and manuscript drafting. AA, SBZE, AD, JD, JME-A and LS were responsible for interpretation of results. EA, AA, SBZE, AD, JD, JME-A and LS were responsible for manuscript review and approval.

Funding This research received no specific grant from any funding agency in the public, commercial or not-for-profit sectors. The Faculty of Medicine at the American University of Beirut paid the publication charges. The authors would like to thank Dr. Mohamed Sayegh for his support.

Competing interests None declared.

Ethics approval The Institutional Review Board (IRB) at the American University of Beirut approved this study.

Provenance and peer review Not commissioned; externally peer reviewed.

Data sharing statement No additional data are available.

Open Access This is an Open Access article distributed in accordance with the Creative Commons Attribution Non Commercial (CC BY-NC 4.0) license, which permits others to distribute, remix, adapt, build upon this work noncommercially, and license their derivative works on different terms, provided the original work is properly cited and the use is non-commercial. See: http:// creativecommons.org/licenses/by-nc/4.0/

\section{REFERENCES}

1. Campbell EG, Rao SR, Desroches CM, et al. Physician professionalism and changes in physician-industry relationships from 2004 to 2009. Arch Intern Med 2010;170:1820-6.

2. Pharmaceutical Research and Manufacture of America (PhRMA) Code on Interactions with Healthcare Professionals. http://journals. plos.org/plosmedicine/article? id=10.1371/journal.pmed.1000352 (accessed 4 Oct 2016).

3. Spurling GK, Mansfield PR, Montgomery BD, et al. Information from pharmaceutical companies and the quality, quantity, and cost of physicians' prescribing: a systematic review. PLoS Med 2010;7: e1000352.
4. Wazana A. Physicians and the pharmaceutical industry: is a gift ever just a gift? JAMA 2000;283:373-80.

5. Safran DG, Taira DA, Rogers $\mathrm{WH}$, et al. Linking primary care performance to outcomes of care. J Fam Pract 1998;47:213-20.

6. Bickell NA, Weidmann J, Fei K, et al. Underuse of breast cancer adjuvant treatment: patient knowledge, beliefs, and medical mistrust. $J$ Clin Oncol 2009;27:5160-7.

7. Carpenter WR, Godley PA, Clark JA, et al. Racial differences in trust and regular source of patient care and the implications for prostate cancer screening use. Cancer 2009;115:5048-59.

8. Lebanese Ministry of Public health Code of Ethics for Medicinal Product Promotion in Lebanon and Implementation Procedure. http:// www.moph.gov.lb/userfiles/files/HealthCareSystem/Pharmaceuticals/ \%D9\%8FEthics/DrugsEthicalStandards/CodeofEthics2016-Final.pdf. (accessed 4 Oct 2016).

9. Green MJ, Masters R, James B, et al. Do gifts from the pharmaceutical industry affect trust in physicians? Fam Med 2012;44:325-31.

10. Jastifer J, Roberts S. Patients' awareness of and attitudes toward gifts from pharmaceutical companies to physicians. Int J Health Serv 2009;39:405-14.

11. Semin S, Guldal D, Ozçakar N, et al. What patients think about promotional activities of pharmaceutical companies in Turkey. Pharm World Sci 2006;28:199-206.

12. Fadlallah $\mathrm{R}, \mathrm{Nas} \mathrm{H}$, Naamani $\mathrm{D}$, et al. Knowledge, beliefs and attitudes of patients and the general public towards the interactions of physicians with the pharmaceutical and the device industry: a systematic review. PLOS ONE 2016;11:e0160540.

13. Qidawai W, Qureshi H, Sohail S, et al. Perceptions on bioethics among patients presenting to family physicians at a teaching hospital in Karachi, Pakistan. Pak J Med Sci 2003;19:192-6.

14. "Lebanon". The World Factbook. Central Intelligence Agency, 2016. https://www.cia.gov/library/publications/resources/the-world-factbook/ geos/le.html. (accessed 8 Oct 2016).

15. Alkhaled L, Kahale L, Nass H, et al. Legislative, educational, policy and other interventions targeting physicians' interaction with pharmaceutical companies: a systematic review. BMJ Open 2014;4: e004880. 